\title{
Influence of Wheat Flour Milling Yield on Physicochemical, Microbial, and Antioxidant Properties of Korea Wheat (Triticum aestivum L. var. Jokyoung)
}

\author{
Sang Sook Kim $\mathbb{D}$, ${ }^{1}$ Yang Soo Byeon $\mathbb{D}^{1,2}$ Mi Jeong Kim $\mathbb{D}^{3,4}$ Dabeen Lee $\mathbb{D}^{\mathrm{D}},{ }^{1}$ \\ and Han Sub Kwak $\mathbb{D D}^{1}$ \\ ${ }^{1}$ Research Group of Food Processing, Korea Food Research Institute, Wanju-gun 55365, Republic of Korea \\ ${ }^{2}$ Department of Biotechnology, College of Life Sciences and Biotechnology, Korea University, Seoul 02841, Republic of Korea \\ ${ }^{3}$ Department of Food and Nutrition, Changwon National University, Changwon-si 51140, Republic of Korea \\ ${ }^{4}$ Interdisciplinary Program in Senior Human Ecology, Changwon National University, Changwon-si 51140, Republic of Korea
}

Correspondence should be addressed to Han Sub Kwak; hskwak@kfri.re.kr

Received 3 June 2020; Revised 6 October 2020; Accepted 9 October 2020; Published 26 October 2020

Academic Editor: Alessandra Durazzo

Copyright $\odot 2020$ Sang Sook Kim et al. This is an open access article distributed under the Creative Commons Attribution License, which permits unrestricted use, distribution, and reproduction in any medium, provided the original work is properly cited.

The physicochemical, microbial, and antioxidant properties of a Korean wheat variety (Jokyoung) were measured according to milling yield (60-90\%) by adding fractions from millstreams. As the milling yield increased, the wheat flour showed low quality on physicochemical properties in general. Significant differences in proximate analysis, color, solvent retention capacity, pasting property, and antioxidant activity were observed as the yield increased to maximize the production of wheat flour from wheat kernels. Adding clear flour and shorts did not significantly affect the quality of the wheat flour in comparison with straight flour samples. However, as brans were added to the flour portion, the wheat flour quality parameters decreased significantly in color, solvent retention capacity, and pasting properties. On the other hand, antioxidant properties increased as brans were added. Maximizing wheat flour yield is a key to minimizing the production cost of Korean wheat flour, which is approximately three times more expensive than imported wheat flour. Adding clear flour and a certain portion of shorts did not seem to significantly influence the overall quality of wheat flour from Korean domestic wheat variety.

\section{Introduction}

Wheat (Triticum aestivum L.) is one of the world's three major grains and accounts for approximately $28 \%$ of total cereal consumption $[1,2]$. In Korea, each individual consumes approximately $32 \mathrm{~kg}$ of wheat per year, and wheat consumption has increased gradually every year [3]. The market share of domestic wheat flour from the local wheat varieties in Korea is below $2 \%$, with the majority of wheat being imported from the USA, Canada, and Australia [3]. For two decades, research institutes, companies, and growers have endeavored to develop new varieties and food products and increase the wheat-growing areas in Korea [4-6]. Food products made from domestic wheat flour are now distributed mainly through local grocery stores and cooperatives, which constitute a different distribution network to that used for conventional wheat products. As a result of these efforts, consumer awareness of Korean wheat flour is favorable and increasing [4].

Several studies on the domestic wheat in Korea have recently been published. Kwak et al. [7] compared the physicochemical properties of 160 imported wheat kernels and 433 domestic wheat kernels over a three-year period. They found that domestic wheat flour had larger variations in the protein content and also showed that many samples had falling numbers below $300 \mathrm{~s}$, which means that the products were not of good quality. In terms of the commercial wheat flour, domestic all-purpose wheat flours are similar to those that are imported [8]. However, domestic baking flours are of a lower quality compared to 
the imported varieties [9]. In a baking study comparing domestic and imported commercial wheat flours, the sensory profiles of pan breads made using imported wheat flours were similar to each other, while the pan breads made from domestic wheat flours showed larger variations in their sensory attributes [10]. Notwithstanding, the range of consumer acceptance ratings for the pan breads made from domestic and imported wheat flours were similar.

T. aestivum L. var. Jokyoung (Jokyoung), a Korean domestic wheat species, was developed in 2004 for baking purposes and can be grown in all regions of the Republic of Korea [11]. Approximately $20 \%$ of farmers grow Jokyoung mainly in the southeast region of the Korean peninsula [12]. Several studies have reported the physicochemical properties of wheat flour and food products made from Jokyoung. The wheat kernels of Jokyoung have a longer length and lower protein and ash contents than the kernels imported from the USA and Canada [13]. Kim et al. [14] reported that the overall baking quality from Jokyoung wheat flour was similar to that of US and Canadian wheat flours. Ham et al. [15] reported that a germinated Jokyoung species showed similar antioxidant activity in DPPH and ABTS assays compared with other domestic wheat varieties, such as Keumkang, Baekjung, and Goso. In application to rice wine making, consumer acceptance of rice wine made with Jokyoung wheat flour was found to be lower than for rice wine made using other wheat species [16].

Milling is a key process to producing wheat flour from wheat kernels. Several studies have been conducted to investigate milling and milling streams in terms of wheat flour quality. The cadmium distribution in millstream was detected mainly in the endosperm when analyzing 16 streams from a Buhler pneumatic laboratory mill for hard winter wheat in the USA [17]. Liao and Chen [18] showed that the SDS-insoluble proteins in wheat millstreams were various and were associated with noodle quality. In Indian wheat, the quality properties were similar for each milling stream, irrespective of the variety [19]. Fustier et al. [20] studied various composition of flours that were middlecut, clear, and produced from soft wheat flour milling for dough and cookie production. The clear millstream fraction was positively correlated with the cookies' hardness and density. Gomez et al. [21] showed that the final stream in their milling should be eliminated due to the negative impact on color, odor, and taste when cakes were made.

Previous milling studies provide evidence that a combination of wheat flour and the byproducts from each milling stream is used to produce the appropriate wheat flour from domestic or imported wheat kernels for each country. Several studies have reported on the physicochemical quality, pasting properties, and food application of wheat flour from one of the major wheat varieties in Korea, Jokyoung. However, no studies have reported for the quality characteristics of wheat flours produced from the various production yields from milling. The objective of this study, therefore, was to investigate the influence of wheat flour yield from milling on the physicochemical, microbial, and antioxidant properties for the Korean wheat variety (Triticum aestivum L. var. Jokyoung).

\section{Materials and Methods}

2.1. Wheat Flour Milling. Wheat kernels (var. Jokyoung) were directly purchased from a local cooperative (Hapcheon-gun, Korea; $\left.35^{\circ} 33^{\prime} 59.8^{\prime \prime} \mathrm{N} 128^{\circ} 09^{\prime} 57.1^{\prime \prime} \mathrm{E}\right)$ located in the southeast of Korean peninsula which is one of the major wheat-growing regions for Jokyoung. The wheat kernels were kept in a refrigerator $\left(4 \pm 1^{\circ} \mathrm{C}\right)$ for 10 days and milled. The wheat kernels were tempered with $16 \%$ moisture content at room temperature for overnight and milled using a test milling machine (Buhler, Braunschweig, Germany), according to the American Association of Cereal Chemists (AACC) method 26-21A [22]. Wheat kernels (40 kg) were put into a test mill at $30 \mathrm{~g} / \mathrm{min}$ for milling. The wheat flours from each step were collected for the three streams of break (B1: $8.1 \%, \mathrm{~B} 2: 7.4 \%$, and B3: $1.8 \%$ ) and the three streams of reduction roll (R1: $26.5 \%, \mathrm{R} 2: 14.0 \%$, and $\mathrm{R} 3: 3.3 \%)$. The weights of the wheat flour of each stream were then measured (Table 1). The straight flour was $61.12 \%$ of the initial weight. The rest was divided into clear flour, wheat shorts, and wheat brans based on the particle size and were composed of $9.6 \%, 8.5 \%$, and $20.7 \%$ wheat flour, respectively. Straight flour, clear, shorts, and wheat brans were added in an consecutive order to produce the samples, which were $60 \%, 65 \%, 70 \%, 75 \%, 80 \%, 85 \%$, and $90 \%$ of the input kernel weight and labeled as Y60, Y65, Y70, Y75, Y80, Y85, and Y90, respectively (Table 2). The samples were tightly packed twice in polyethylene bags and stored at $0^{\circ} \mathrm{C}$ until used.

2.2. Physicochemical Properties of the Wheat Flour Samples. The moisture, protein, and ash contents of the samples were measured according to AACC methods [20]. Wheat flour (3 (g) was put into a $130^{\circ} \mathrm{C}$ dry oven for 24 hours to measure its moisture content (AACC method 44-15A). Crude protein was measured according to the micro-Kjeldahl method (AACC method 46-12) using a Kjeltec autosampler system 1035 analyzer (Tecator Co., Hoganas, Sweden). The crude protein content was obtained by multiplying the nitrogen content and nitrogen conversion factor (5.95). The wheat flour was heated at $600^{\circ} \mathrm{C}$ for 12 hours to measure the ash content (AACC method 08-01). The experiments were conducted in triplicate. The Hunter color (L, a, and b) of the wheat flour was measured five times using a portable spectrophotometer (Spectrophotometer CM-700d, Minolta Co., Osaka, Japan).

\subsection{Solvent Retention Capacity Profile of the Wheat Flour} Samples. The solvent retention capacity (SRC) profile of wheat flour consists of its sodium carbonate SRC (SCSRC), sucrose SRC (SSRC), lactic acid SRC (LASRC), and water retention capacity (WRC) values. These were measured according to the method proposed by Duyvejonck et al. [23], which is a modification of the AACC method 56-11A [22]. Briefly, $25 \mathrm{~mL}$ of a $5 \%(\mathrm{v} / \mathrm{v})$ sodium carbonate solution, a $50 \%(\mathrm{w} / \mathrm{w})$ sugar solution, a $5 \%(\mathrm{w} / \mathrm{w})$ lactic acid 
TABLE 1: Weights and compositions for individual flour stream of wheat (var. Jokyoung) by Buhler laboratory mill and composition.

\begin{tabular}{lccc}
\hline Milling stream $^{1}$ & Weight $(\mathrm{kg})$ & Composition (\%) & Cumulative composition (\%) \\
\hline B1 & 3.16 & 8.05 & 8.05 \\
B2 & 2.92 & 7.44 & 15.49 \\
B3 & 0.71 & 1.81 & 17.30 \\
R1 & 10.40 & 26.50 & 43.80 \\
R2 & 5.50 & 14.01 & 57.81 \\
R3 & 1.30 & 3.31 & 61.12 \\
Clear flour & 3.78 & 9.63 & 70.75 \\
Short & 3.34 & 8.51 & 79.26 \\
Bran & 8.14 & 20.74 & 100.00 \\
Total & 39.25 & 100.00 & \\
\hline
\end{tabular}

${ }^{1} \mathrm{~B} 1, \mathrm{~B} 2$, and $\mathrm{B} 3$ and R1, R2, and R3 are flours from three break rollers and three reduction rollers by Buhler laboratory mill, respectively.

TABLE 2: Millstream composition (\%) of the wheat flour samples that had $60-90 \%$ yields.

\begin{tabular}{lcccccccc}
\hline Fraction & $\begin{array}{c}\text { Composition } \\
(\%)\end{array}$ & \multicolumn{6}{c}{ Yample composition $(\%)$} \\
& 8.9 & 8.1 & 8.1 & 8.1 & 8.1 & 8.1 & 8.1 & 8.1 \\
B1 & 7.3 & 7.4 & 7.4 & 7.4 & 7.4 & 7.4 & 7.4 & 7.4 \\
B2 & 1.4 & 1.8 & 1.8 & 1.8 & 1.8 & 1.8 & 1.8 & 1.8 \\
B3 & 24.1 & 26.5 & 26.5 & 26.5 & 26.5 & 26.5 & 26.5 & 26.5 \\
R1 & 10.7 & 14.0 & 14.0 & 14.0 & 14.0 & 14.0 & 14.0 & 14.0 \\
R2 & 3.1 & 2.2 & 3.3 & 3.3 & 3.3 & 3.3 & 3.3 & 3.3 \\
R3 & 16.2 & & 3.9 & 8.9 & 9.6 & 9.6 & 9.6 & 9.6 \\
Clear & & & & & & & & \\
flour & 8.0 & & & & 4.4 & 8.5 & 8.5 & 8.5 \\
Short & 20.4 & & & & & 0.8 & 5.8 & 10.8 \\
Bran & 100.0 & 60.0 & 65.0 & 70.0 & 75.0 & 80.0 & 85.0 & 90.0 \\
Sum & & & & & & & & \\
\hline
\end{tabular}

solution, and distilled water were used for the SCSRC, SSRC, LASRC, and WRC measurements, respectively. Flour ( $5 \mathrm{~g}$ ) was added to the solvent, mixed for 20 minutes, and then centrifuged at $6000 \times \mathrm{g}$. The SRC values were obtained from the weight of the precipitate after removing the supernatant.

2.4. Rapid Visco Analysis of the Wheat Flour Samples. For the rapid visco analysis (RVA), $3.5 \mathrm{~g}$ of wheat flour, which was adjusted to a $14 \%$ moisture basis, was blended with $25 \mathrm{~mL}$ of distilled water according to the AACC method 76-21 [22]. After blending, the wheat flour slurry was transferred to a rapid visco analyzer (RVA Model 3D, Newport Scientific, Warriewood, Australia). The analysis was conducted according to the manufacturer's manual. The pasting properties of the wheat flour slurry were measured as dry weight $(\mathrm{dw})$. The analyzer was set at $50^{\circ} \mathrm{C}$ as the starting temperature and kept at this temperature for 1 minute. The slurry was then heated to $95^{\circ} \mathrm{C}$ at a rate of $6^{\circ} \mathrm{C} /$ minute and maintained at $95^{\circ} \mathrm{C}$ for 2 minutes. The temperature of the slurry went down to $50^{\circ} \mathrm{C}$ at a rate of $6^{\circ} \mathrm{C} /$ minute. The paste viscosity properties of the wheat flour were peak viscosity (the maximum viscosity while heating the wheat slurry), trough viscosity (the minimum viscosity after the peak viscosity measurement), and final viscosity (the viscosity of the paste after cooling). All the values were recorded in centipoise (cP). Two derived viscosity values, namely, breakdown viscosity (the peak viscosity minus the trough viscosity) and setback viscosity (SB; the final viscosity minus the peak viscosity), were also calculated. Additionally, the pasting temperature and peak time were recorded. The measurements were undertaken in triplicate.

2.5. Differential Scanning Calorimetry. The transition properties of the wheat flour samples were measured with a differential scanning calorimeter (DSC 7, Perkin-Elmer Co., Waltham, MA, USA) following the method of Lund and Lorenz [24]. The calorimeter was calibrated using an indium standard. The wheat flour samples (approximately $12 \mathrm{mg}$ ) were weighted into DSC stainless pans, and deionized water was added to obtain a wheat flour/water ratio of $3: 7(\mathrm{w} / \mathrm{v})$. The pans were sealed and equilibrated at room temperature for $1 \mathrm{~h}$. The samples were then cooled down at $10^{\circ} \mathrm{C}$ for $1 \mathrm{~min}$ and heated to $130^{\circ} \mathrm{C}$ at a heating rate of $10^{\circ} \mathrm{C} / \mathrm{min}$. An empty aluminum pan was used as a reference. The thermal transition parameters (onset, peak, conclusion and end temperatures and enthalpy change $(\Delta \mathrm{H})$ ) were determined from the data recording software. All the measurements were performed in triplicate.

2.6. Microbiological Testing of the Wheat Flour Samples. The aerobic plate count (APC) of the wheat flour was determined using a $3 \mathrm{M}$ APC Petrifilm (3M Co. Ltd., St. Louis, MO, USA), and the yeast and mold (YM) were counted using a 3M YM count plate Petrifilm (3M). A flour sample $(10 \mathrm{~g})$ and sterilized $0.85 \% \mathrm{NaCl}$ solution $(90 \mathrm{~mL})$ were put into a stomacher (HG 400, Wiggens Co., Ltd., Beijing, China) and homogenized for 10 minutes. Serial 10 -fold dilutions were carried out using a sterilized $0.85 \% \mathrm{NaCl}$ solution. Homogenates $(1 \mathrm{~mL})$ were spread on the $3 \mathrm{M}$ Petrifilm and put into incubators-APC at $35^{\circ} \mathrm{C}$ for 48 hours and YM count plate Petrifilm at $25^{\circ} \mathrm{C}$ for 72 hours-for colony counting. The colonies were converted to $\log \mathrm{CFU} / \mathrm{g}$.

2.7. DPPH Radical Scavenging Activity and Total Polyphenol Content. The DPPH radical scavenging activity (RSA) is one of the methods to identify antioxidant activity for wheat flour, wheat roasting, polished wheat, and baked products $[2,24-26]$. The DPPH RSA of the wheat flour samples was measured according to the methods from Brand-William 
et al. [27, 28]. Briefly, wheat flour ( $5 \mathrm{~g}, 14 \% \mathrm{w} / \mathrm{w}$ moisture content) was mixed with $50 \mathrm{~mL}$ of a methanol solution $(80 \%$, $\mathrm{v} / \mathrm{v}$ ) and blended at $37^{\circ} \mathrm{C}$ in a constant-temperature waterbath at $100 \mathrm{rpm}$ for 2 hours for extraction. The mixture was vacuum-filtered using a Whatman No. 2 filter (Whatman plc, Maidstone, UK) and centrifuged at 7,165 $\times \mathrm{g}$. The supernatant was evaporated using an evaporator (HS-2001N, Hahshin Science Co., Jeonju -si, Korea) until the volume of the supernatant was below $5 \mathrm{~mL}$. After evaporation, $80 \%(\mathrm{v} / \mathrm{v})$ methanol was added to the volume of $10 \mathrm{~mL}$ and was then filtered using a $0.45 \mu \mathrm{m}$ filter (Merck, Darmstadt, Germany) for DPPH analysis. The extraction $(0.1 \mathrm{~mL})$ was blended with a $6 \times 10^{-5} \mathrm{~mol} / \mathrm{L}$ DPPH solution at room temperature in the dark. After 30 minutes, the absorbance was measured at $515 \mathrm{~nm}$ using a SpectraMax ${ }^{\circledR} \mathrm{i} 3$ plate reader (Molecular Devices, Sunnyvale, CA, USA). The methanol solution $(80 \%, \mathrm{v} / \mathrm{v})$ was used as a control. The DPPH RSA (\%) was calculated based on the following formula:

$$
\operatorname{DPPHRSA}(\%)=\left(\frac{1-\text { Asample } / t=30 \mathrm{~min}}{\text { Asample } / t=30 \mathrm{~min} A}\right) \times 100 \text {. }
$$

The total polyphenol content (TPC) of the wheat flour samples was measured according to the methods proposed by Hung et al. [2] and Gujral et al. [29]. Briefly, wheat flour ( $10 \mathrm{~g}, 14 \% \mathrm{w} / \mathrm{w}$ moisture content) was mixed with a $50 \mathrm{~mL}$ methanol solution $(80 \%, v / v)$ and blended at $60^{\circ} \mathrm{C}$ in a constant-temperature waterbath at $100 \mathrm{rpm}$ for 3 hours for extraction. The mixture was vacuum-filtered using a Whatman No. 2 filter (Whatman plc, Maidstone, UK) and centrifuged at 3,000 rpm for 15 minutes. The supernatant was evaporated using an evaporator (HS-2001N, Hahshin Science Co., Bucheon-si, Korea) until the volume of the supernatant was below $1 \mathrm{~mL}$. The concentrated extraction $(100 \mu \mathrm{L})$, Folin-Ciocalteu reagent $(500 \mu \mathrm{L})$, and $20 \%$ sodium carbonate $(1.5 \mathrm{~mL})$ were blended. Thereafter, distilled water was added until the volume was $10 \mathrm{~mL}$, and the solution was kept at room temperature for 2 hours. The absorbance was measured at $765 \mathrm{~nm}$ using a spectrophotometer (V-650, JASCO, Easton, MA, USA), and an ethanol solution $(80 \%, \mathrm{v} / \mathrm{v})$ was used as a control. The total polyphenol content was calculated as the gallic acid equivalent (GAE)/g of wheat flour (dwb).

2.8. Statistical Analysis. Analysis of variance (ANOVA) was performed to determine the differences among the samples using the XLSTAT software version 2016 (Addinsoft, Paris, France). When significant differences were found among the samples, Fisher's least significant difference test was conducted to separate the means at $p<0.05$.

\section{Results and Discussion}

3.1. Physicochemical Properties. The physiochemical properties of the wheat flour samples in terms of color, moisture, protein, ash, and fat content are presented in Table 3. The moisture content was $11.88-12.12 \%(w / w)$, and there was no significant difference across the samples $(p>0.05)$. The addition of shorts and brans to the flour did not influence the moisture content of the wheat flour. The protein, ash, and fat contents were $12.91-14.04 \%, 0.42-0.97 \%$, and $0.61-1.11 \%$, respectively. These were increased significantly $(p<0.05)$ as the clear flour, shorts, and brans were added in that order. The increases were because of the relatively higher contents of protein, ash, and fat in the shorts and brans of the wheat kernel rather than the endosperm $[30,31]$. The protein content of the white flour samples (Y60-Y70) was approximately $13 \%$ and meets the requirement of bakingpurpose wheat flour. The grade of the wheat flour in Korea is determined by its ash content. The Y60-Y75 samples were below $0.6 \%$, which indicated first-grade wheat flour. The shorts-containing samples, Y80 and Y85, had $0.67 \%$ and $0.86 \%$ ash content, respectively, indicating second-grade wheat flour (0.6-0.9\% of ash). The rest of the samples were found to be third grade, as they had an ash content above $0.9 \%$ [32]. In terms of the color of the flour, $L$ value, $a$ value, and $b$ values were 90.06-95.14, 0.21-1.37, and 8.61-9.59, respectively. Lightness $(L)$ was significantly decreased from the Y80 samples $(p<0.05)$, while redness (a) was significantly increased $(p<0.05)$ due to the addition of the shorts and brans that have a reddish color. The yellowness of the flours did not show an increased or decreased trend. Furthermore, the whiteness of the flour showed a similar trend to the lightness, decreasing from 79.20 (Y60) to 67.33 (Y90). The particle size of each sample ranged 15.7-25.7 $\mu \mathrm{m}$ and was similar to the Chinese wheat flour [33].

3.2. Solvent Retention Capacity. The SRCs of the wheat flour from Jokyoung according to milling yields are shown in Table 4. According to Kweon et al. [33], starch damage is related to the SCSRC. The SCSRC was lowest in the Y60 sample at $60.80 \%$, but gradually increased to $86.02 \%$ in the Y90 sample.

The gold standard target for the SCSRC is below 72\% for sponge and dough products [33], and the Y60-Y80 samples met this standard. The SCSRC increased drastically from Y85 due to the addition of brans to the wheat flour, which negatively influences starch damage [34]. According to Lindgren and Simsek [35], the arabinoxylan content is related to the SUSRC. As the milling yield increased, the SUSRC increased, which meant that the Y80-Y90 samples had a higher arabinoxylan content that existed in shorts and brans. Below $96 \%$ of the SUSRC is recommended for baking purpose [33], and all the samples were below this standard. The LASRC is the indicator of the gluten quality of wheat flour [34]. In this study, the LASRC decreased as the milling yield increased. The Y60-Y70 samples had the LASRCs above $118 \%$ but decreased significantly from the Y75 sample as the shorts and brans were added $(p<0.05)$. Y60-Y75 have above $100 \%$ of the LASRC, which is the gold standard target [33]. The WRC reflects the water absorption in wheat flour and recommended below $57 \%$ for baking purpose $[24,36]$. The Y60-Y75 samples, which did not contain shorts or brans, had similar WRCs to the Korean commercial baking flour samples [9]. As the brans were added to the flour, the 
TABle 3: Moisture, protein, ash and fat contents, color, and whiteness of wheat flour (var. Jokyoung) according to flour yield.

\begin{tabular}{|c|c|c|c|c|c|c|c|c|}
\hline \multirow{2}{*}{ Yield (\%) } & \multirow{2}{*}{ Moisture (\%) } & \multirow{2}{*}{ Protein $(\%)^{1)}$} & \multirow{2}{*}{$\operatorname{Ash}(\%)^{1)}$} & \multirow{2}{*}{ Fat $(\%)^{1)}$} & \multicolumn{3}{|c|}{ Color } & \multirow{2}{*}{ Whiteness } \\
\hline & & & & & $\mathrm{L}$ & $\mathrm{a}$ & $\mathrm{b}$ & \\
\hline Y60 & $11.85 \pm 0.16^{\mathrm{ns} 2)}$ & $12.94 \pm 0.04^{\mathrm{de} 3)}$ & $0.43 \pm 0.04^{\mathrm{e}}$ & $0.61 \pm 0.03^{\mathrm{b}}$ & $95.14 \pm 0.18^{\mathrm{a}}$ & $0.21 \pm 0.04^{\mathrm{c}}$ & $9.18 \pm 0.23^{\mathrm{abc}}$ & $79.20 \pm 0.10^{\mathrm{a}}$ \\
\hline Y65 & $12.11 \pm 0.38$ & $12.91 \pm 0.00^{\mathrm{e}}$ & $0.43 \pm 0.02^{\mathrm{e}}$ & $0.93 \pm 0.09^{\mathrm{a}}$ & $95.22 \pm 0.78^{\mathrm{a}}$ & $0.34 \pm 0.05^{\mathrm{bc}}$ & $9.05 \pm 0.48^{\mathrm{abc}}$ & $78.93 \pm 0.06^{\mathrm{a}}$ \\
\hline Y70 & $11.81 \pm 0.11$ & $13.01 \pm 0.01^{\mathrm{d}}$ & $0.42 \pm 0.06^{\mathrm{e}}$ & $1.04 \pm 0.24^{\mathrm{a}}$ & $95.59 \pm 0.63^{\mathrm{a}}$ & $0.29 \pm 0.08^{\mathrm{c}}$ & $8.67 \pm 0.18^{\mathrm{bc}}$ & $78.43 \pm 0.15^{\mathrm{b}}$ \\
\hline Y75 & $11.88 \pm 0.48$ & $13.18 \pm 0.10^{\mathrm{c}}$ & $0.52 \pm 0.00^{\mathrm{d}}$ & $1.07 \pm 0.03^{\mathrm{a}}$ & $94.70 \pm 1.02^{\mathrm{ab}}$ & $0.33 \pm 0.11^{b c}$ & $8.61 \pm 0.12^{c}$ & $76.97 \pm 0.15^{\mathrm{c}}$ \\
\hline Y80 & $12.12 \pm 0.64$ & $13.74 \pm 0.01^{\mathrm{b}}$ & $0.67 \pm 0.05^{\mathrm{c}}$ & $1.04 \pm 0.06^{\mathrm{a}}$ & $93.33 \pm 0.85^{\mathrm{b}}$ & $0.62 \pm 0.19^{b}$ & $9.05 \pm 0.61^{\mathrm{abc}}$ & $74.57 \pm 0.06^{\mathrm{d}}$ \\
\hline Y85 & $11.75 \pm 0.40$ & $13.78 \pm 0.07^{\mathrm{b}}$ & $0.86 \pm 0.05^{\mathrm{b}}$ & $1.04 \pm 0.05^{\mathrm{a}}$ & $91.11 \pm 1.39^{c}$ & $1.12 \pm 0.29^{\mathrm{a}}$ & $9.46 \pm 0.87^{\mathrm{ab}}$ & $70.03 \pm 0.55^{\mathrm{e}}$ \\
\hline Y90 & $11.75 \pm 0.40$ & $14.04 \pm 0.05^{\mathrm{a}}$ & $0.97 \pm 0.03^{\mathrm{a}}$ & $1.11 \pm 0.08^{\mathrm{a}}$ & $90.06 \pm 0.27^{\mathrm{c}}$ & $1.37 \pm 0.29^{\mathrm{a}}$ & $9.59 \pm 0.15^{\mathrm{a}}$ & $67.33 \pm 0.06^{\mathrm{f}}$ \\
\hline
\end{tabular}

${ }^{1)}$ Protein, ash, and fat contents were revised based on $14 \%$ of a moisture content of wheat flour. ${ }^{2)}$ 'ns' means no significant difference across the samples at $p<0.05$ by Fisher's least significant difference test. ${ }^{3)}$ Mean values with different superscripts within each column are significantly different across the samples at $p<0.05$ by Fisher's least significant difference test.

TABLE 4: Solvent retention capacity of wheat flour (var. Jokyoung) according to flour yield.

\begin{tabular}{lcccc}
\hline Yield (\%) & SCSRC $^{1)}$ & SUSRC & LASRC & WRC \\
\hline Y60 & $60.80 \pm 1.97^{\mathrm{e} 2)}$ & $84.42 \pm 2.69^{\mathrm{e}}$ & $119.57 \pm 0.22^{\mathrm{a}}$ & $55.92 \pm 1.59^{\mathrm{d}}$ \\
Y65 & $61.73 \pm 0.22^{\mathrm{e}}$ & $87.82 \pm 0.44^{\mathrm{cd}}$ & $119.29 \pm 1.85^{\mathrm{a}}$ & $56.36 \pm 0.47^{\mathrm{cd}}$ \\
Y70 & $62.41 \pm 1.47^{\mathrm{e}}$ & $86.96 \pm 0.05^{\mathrm{d}}$ & $118.89 \pm 1.72^{\mathrm{a}}$ & $108.06 \pm 0.41^{\mathrm{b}}$ \\
Y75 & $65.57 \pm 0.95^{\mathrm{d}}$ & $88.44 \pm 1.22^{\mathrm{cd}}$ & $97.64 \pm 0.73^{\mathrm{c}}$ & $55.61 \pm 1.30^{\mathrm{d}}$ \\
Y80 & $69.46 \pm 0.87^{\mathrm{c}}$ & $89.37 \pm 1.28^{\mathrm{bc}}$ & $86.72 \pm 0.70^{\mathrm{d}}$ & $57.64 \pm 0.10^{\mathrm{d}}$ \\
Y85 & $80.16 \pm 1.45^{\mathrm{b}}$ & $90.80 \pm 0.28^{\mathrm{ab}}$ & $61.84 \pm 0.70^{\mathrm{b}}$ \\
Y90 & $86.02 \pm 0.30^{\mathrm{a}}$ & $92.33 \pm 0.59^{\mathrm{a}}$ & $80.31 \pm 0.89^{\mathrm{e}}$ & $64.79 \pm 0.38^{\mathrm{a}}$ \\
\hline
\end{tabular}

${ }^{1)}$ SCSRC, SUSRC, LASRC, GPI, and WRC mean sodium carbonate SRC, sucrose SRC, lactic acid SRC, gluten performance index, and water retention capacity, respectively. ${ }^{2)}$ Mean values with different superscripts within each column are significantly different across the samples at $p<0.05$ by Fisher's least significant difference test.

WRC increased significantly $(p<0.05)$, and the WRC was over $80 \%$ from Y80. This increase of the WRC generates lower-quality paste properties due to the high moisture content of the paste. Schmiele et al. [37] reported that bread quality is reduced as more whole-wheat flour is added to the bread. Therefore, maximizing milling yield for cost-benefit would generate low-quality wheat flour and also influence its paste properties.

\subsection{Pasting Properties of the Wheat Flour Samples by RVA.} The pasting properties of wheat flour by RVA represents the flour quality based on starch swelling, retrogradation, and gelatinization [38]. The peak, trough, and final viscosities, breakdown and setback values, peak times, and pasting temperatures of the wheat flour samples in this study are shown in Table 5. All the parameters, except the pasting temperatures, showed significant differences among the samples $(p<0.05)$ and decreased as milling yield increased in general. Y60-Y70, which contained only flour parts, showed consistent ranges for the peak, trough, and final viscosities as 916.0-1367.3 cP, 580.3-952.7 cP, and 1274.0-1831.7 cP, respectively. The flour part samples, Y60-Y70, showed similar $\mathrm{cP}$ results compared to commercial Korean wheat flour used for baking purposes [9]. When the shorts and brans were added in the Y75-Y90 samples, the peak, trough, and final viscosities dropped significantly to $916.0 \mathrm{cP}, 580.3 \mathrm{cP}$, and $335.7 \mathrm{cP}$, respectively. According to Blazek and Copeland [39], peak and trough viscosities are related to the swelling power of dough. In this study, as the flour yield increased, the dough quality decrease due to the addition of the shorts and brans. The setback value represents starch retrogradation [40]. The setback values were above $840 \mathrm{cP}$ for the Y60-Y75 samples, but as large volumes of shorts and brans were added from Y80, the values dropped significantly to $673.7 \mathrm{cP}$. Moisture content, the ratios of amylose and amylopectin, the interaction of starch and protein, and temperature affect starch retrogradation [40-42]. In this study, starch retrogradation was prevented due to the fibers in shorts and brains, which inhibit recrystallization of amylose chains. The trend was also reported that the final millstream had a lower setback value in wheat flour milling [21]. There was no significant difference in the peak times for the Y60-Y70 samples at 5.9-6.0 minutes $(p>0.05)$.

Lindgren and Simsek [35] reported that the peak times in the white flour parts were not significantly different across the millstreams. The peak time in this study gradually decreased from the Y75 $(5.8 \mathrm{~min})$ to the Y90 sample $(5.5 \mathrm{~min} ; p<0.05)$. This was due to the low peak viscosity as the flour yield increased. There was no significant difference across the samples for the pasting temperature $(p>0.05)$. The results of the pasting properties of the samples showed similar trends to those of the SRCs (Table 4), with lower variations among the Y60-70 samples, which comprised only straight and clear flours as the results from the negative correlation of SRC and RVA characteristics [35]. The RVA results of these samples had similar physicochemical properties to commercial bakingpurpose flour [9]. Therefore, considering Jokyoung variety 
TABLE 5: Pasting properties by a rapid visco-analyzer of wheat flour (var. Jokyoung) according to flour yield.

\begin{tabular}{|c|c|c|c|c|c|c|c|}
\hline $\begin{array}{l}\text { Yield } \\
(\%)\end{array}$ & $\begin{array}{l}\text { Peak viscosity } \\
\text { (cP) }\end{array}$ & $\begin{array}{l}\text { Trough viscosity } \\
\text { (cP) }\end{array}$ & $\begin{array}{l}\text { Breakdown } \\
(\mathrm{cP})\end{array}$ & $\begin{array}{l}\text { Final viscosity } \\
\text { (cP) }\end{array}$ & Setback (cP) & $\begin{array}{l}\text { Peak time } \\
\text { (min) }\end{array}$ & $\begin{array}{l}\text { Pasting temperature } \\
\left({ }^{\circ} \mathrm{C}\right)\end{array}$ \\
\hline Y60 & $1338.0 \pm 23.5^{\mathrm{ab}}$ & $928.3 \pm 10.1^{\mathrm{a}}$ & $409.7 \pm 15.5^{\mathrm{ab}}$ & $1802.7 \pm 21.9^{\mathrm{a}}$ & $874.3 \pm 11.8^{\mathrm{a}}$ & $5.9 \pm 0.0^{\mathrm{a}}$ & $89.0 \pm 0.1^{\mathrm{NS}}$ \\
\hline Y65 & $1367.3 \pm 2.1^{\mathrm{a}}$ & $952.7 \pm 5.1^{\mathrm{a}}$ & $414.7 \pm 3.1^{\mathrm{a}}$ & $1831.7 \pm 3.8^{\mathrm{a}}$ & $879.0 \pm 3.0^{\mathrm{a}}$ & $6.0 \pm 0.0^{\mathrm{a}}$ & $89.0 \pm 0.0$ \\
\hline Y70 & $1321.7 \pm 35.5^{\mathrm{b}}$ & $951.3 \pm 35.1^{\mathrm{a}}$ & $370.3 \pm 36.1^{\mathrm{c}}$ & $1795.7 \pm 22.9^{\mathrm{a}}$ & $844.3 \pm 38.4^{\mathrm{a}}$ & $6.0 \pm 0.2^{\mathrm{a}}$ & $88.5 \pm 1.1$ \\
\hline Y75 & $1249.7 \pm 46.7^{\mathrm{c}}$ & $839.3 \pm 30.0^{b}$ & $410.3 \pm 21.1^{\mathrm{a}}$ & $1680.7 \pm 65.9^{b}$ & $841.3 \pm 41.2^{\mathrm{a}}$ & $5.8 \pm 0.0^{\mathrm{b}}$ & $88.7 \pm 0.4$ \\
\hline Y80 & $1105.0 \pm 18.0^{\mathrm{d}}$ & $728.3 \pm 12.9^{c}$ & $376.7 \pm 7.6^{\mathrm{bc}}$ & $1491.7 \pm 25.3^{c}$ & $763.3 \pm 13.0^{\mathrm{b}}$ & $5.7 \pm 0.0^{\mathrm{bc}}$ & $88.7 \pm 0.5$ \\
\hline Y85 & $992.3 \pm 11.0^{\mathrm{e}}$ & $635.7 \pm 16.5^{\mathrm{d}}$ & $356.7 \pm 10.0^{\mathrm{cd}}$ & $1350.3 \pm 21.2^{\mathrm{d}}$ & $714.7 \pm 5.5^{\mathrm{c}}$ & $5.6 \pm 0.1^{\mathrm{cd}}$ & $89.2 \pm 0.8$ \\
\hline Y90 & $916.0 \pm 16.6^{\mathrm{f}}$ & $580.3 \pm 14.4^{\mathrm{e}}$ & $335.7 \pm 19.7^{\mathrm{d}}$ & $1274.0 \pm 43.6^{\mathrm{e}}$ & $693.7 \pm 33.2^{c}$ & $5.5 \pm 0.1^{\mathrm{d}}$ & $89.3 \pm 0.4$ \\
\hline
\end{tabular}

${ }^{1)}$ Mean values with different superscripts within each column are significantly different across the samples at $p<0.05$ by Fisher's least significant difference test.

TABLE 6: Phase transition properties of wheat flour (var. Jokyoung) according to flour yield by differential scanning calorimetry (DSC).

\begin{tabular}{lcccc}
\hline Yield (\%) & Onset temperature $\left({ }^{\circ} \mathrm{C}\right)$ & Peak temperature $\left({ }^{\circ} \mathrm{C}\right)$ & End temperature $\left({ }^{\circ} \mathrm{C}\right)$ & $\Delta \mathrm{H}(\mathrm{J} / \mathrm{g})$ \\
\hline Y60 & $61.1 \pm 0.9^{\mathrm{ns} 1)}$ & $65.0 \pm 0.4^{\mathrm{ns}}$ & $69.5 \pm 0.7^{\mathrm{ab} 2)}$ & $69.0 \pm 1.3^{\mathrm{ab}}$ \\
Y65 & $60.9 \pm 1.4$ & $65.0 \pm 0.5$ & $67.6 \pm 0.4^{\mathrm{b}}$ & $10.0 \pm 3.1^{\mathrm{ab}}$ \\
Y70 & $61.4 \pm 1.1$ & $65.2 \pm 0.5$ & $68.8 \pm 1.1^{\mathrm{ab}}$ & $5.6 \pm 2.1^{\mathrm{b}}$ \\
Y75 & $61.8 \pm 2.4$ & $65.1 \pm 0.9$ & $70.8 \pm 3.6^{\mathrm{a}}$ & $5.6 \pm 1.1^{\mathrm{b}}$ \\
Y80 & $61.4 \pm 2.1$ & $65.7 \pm 0.6$ & $69.6 \pm 0.2^{\mathrm{ab}}$ & $8.0 \pm 1.8^{\mathrm{ab}}$ \\
Y85 & $60.9 \pm 1.6$ & $65.3 \pm 0.9$ & $70.2 \pm 1.6^{\mathrm{ab}}$ & $8.3 \pm 2.1^{\mathrm{ab}}$ \\
Y90 & $62.4 \pm 1.9$ & $65.7 \pm 1.3$ & $4.9 \pm 2.0^{\mathrm{b}}$ \\
\hline
\end{tabular}

1) $n$ s' means no significant difference across the samples at $p<0.05$ by Fisher's least significant difference test. ${ }^{2)}$ Mean values with different superscripts within each column are significantly different across the samples at $p<0.05$ by Fisher's least significant difference test.

is used for baking purpose, the addition of shorts and brans should be carefully managed for dough and baking qualities.

\subsection{Thermal Transition Properties by Differential Scanning} Calorimetry. The onset, peak, and end temperatures and enthalpy changes $(\Delta \mathrm{H})$ during gelatinization of the wheat flour samples according to milling yield are shown in Table 6 . There was no statistical significance in the onset and peak temperatures across the samples $(p>0.05)$ as $60.9-61.8^{\circ} \mathrm{C}$ and $65.0-65.7^{\circ} \mathrm{C}$, respectively. These results were similar to those for commercial domestic wheat flour for baking purposes, which showed onset temperatures of $59.5-59.8^{\circ} \mathrm{C}$ and peak temperatures of $64.9-65.2^{\circ} \mathrm{C}$ [9], and different ranges were similar to Chinese wheat flour [33], which used a single variety study with various millstreams. The onset temperature is related to the melting of the least stable starch crystallites [43], and the addition of clear flour, shorts, and brans did not affect the melting of starch crystallites. The end temperatures were $67.6-70.8^{\circ} \mathrm{C}$ and were significantly different among the samples. The wheat flour only sample (Y60-Y70) had a relatively lower end temperature, but there was no distinctive increasing or decreasing pattern based on flour yield. The $\Delta \mathrm{H}$ is the energy necessary to melt starch crystallites when water is present [44]. The $\Delta \mathrm{H}$ ranged between $4.9 \mathrm{~J} / \mathrm{g}$ for Y90 and $10.0 \mathrm{~J} / \mathrm{g}$ for Y65. Since there was no increasing or decreasing patterns, it is difficult to conclude that the addition of clear flour, shorts, and brans influenced the melting of starch crystallites. Overall, the above thermal transition results showed that the starch granules of each sample had similar thermal properties. The addition of shorts and brans to Y75-Y90 did not influence the thermal properties of the wheat flour. This could be due to the use of the same wheat kernels for milling and combining for wheat flour. Different millstreams using the same kernels displayed similar thermal transition properties for spring and winter wheat and rye in Sweden $[45,46]$.

3.5. Microbial Properties of the Wheat Flour Samples. The microorganisms in wheat flour proliferate because of the heat and moisture generated during milling, negatively influence wheat flour quality and cause food-poisoning $[30,47,48]$. Especially, the above $\log 5 \mathrm{CFU} / \mathrm{g}$ may lower the flour quality and cause foodborne disease [48]. The results of the APC, mold (MC), and yeast (YC) counts in the wheat flour samples are shown in Table 7. The APC was the highest in $\mathrm{Y} 60$ at $4.11 \mathrm{log}$ CFU/g and the lowest in Y65 at $2.71 \mathrm{log}$ $\mathrm{CFU} / \mathrm{g}$. There was no distinctive trend in the APC across the samples. In terms of the FC, the fungi were between 2.79 and $3.01 \log \mathrm{CFU} / \mathrm{g}$ and also showed no distinctive increasing or decreasing trend across the samples. These results were similar to the previous to the two Jokyoung varieties that showed the APC and MC for two Jokyoung kernels were 3.76 and $4.27 \mathrm{log} \mathrm{CFU} / \mathrm{g}$ and 2.52 and $3.56 \mathrm{log} \mathrm{CFU} / \mathrm{g}$, respectively [13]. The YC in the wheat flour samples were 1.90-2.80 log CFU/g, and there were no significant differences among the samples. The levels of mold and yeast were below $\log 5 \mathrm{CFU} / \mathrm{g}$ [48]; therefore, the samples in this study were below the maximum limits and were microbially safe, although brans were added. In a microbial study of 71 Australian wheat flour samples, the APC was 1-7 log CFU/g, the $\mathrm{MC}$ was 2-3 $\log \mathrm{CFU} / \mathrm{g}$, and the $\mathrm{YC}$ was $2-3 \log \mathrm{CFU} / \mathrm{g}$ 
TABLE 7: Total aerobic, mold, and yeast counts of wheat flour (var. Jokyoung) according to flour yield.

\begin{tabular}{lccc}
\hline Yield (\%) & Total aerobic count $(\log$ CFU/g) & Mold $(\log$ CFU/g) & Yeast (log CFU/g) \\
\hline Y60 & $4.11 \pm 0.00^{\text {al }}$ & $3.01 \pm 0.06^{\text {ns2 })}$ & $2.52 \pm 0.24^{\text {ns }}$ \\
Y65 & $2.71 \pm 0.07^{\mathrm{e}}$ & $2.86 \pm 0.37$ & $1.90 \pm 1.65$ \\
Y70 & $2.78 \pm 0.01^{\mathrm{d}}$ & $2.97 \pm 0.03$ & $2.80 \pm 0.04$ \\
Y75 & $3.87 \pm 0.02^{\mathrm{b}}$ & $3.00 \pm 0.04$ & $2.46 \pm 0.15$ \\
Y80 & $2.82 \pm 0.02^{\text {cd }}$ & $2.79 \pm 0.10$ & $2.10 \pm 0.17$ \\
Y85 & $2.84 \pm 0.03^{\mathrm{c}}$ & $2.90 \pm 0.05$ & $2.49 \pm 0.20$ \\
Y90 & $3.83 \pm 0.02^{\mathrm{b}}$ & $2.90 \pm 0.00$ & $2.71 \pm 0.24$ \\
\hline
\end{tabular}

${ }^{1)}$ Mean values with different superscripts within each column are significantly different across the samples at $p<0.05$ by Fisher's least significant" difference

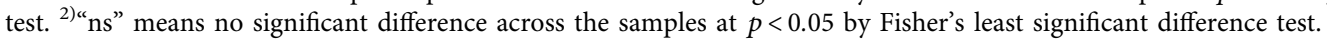

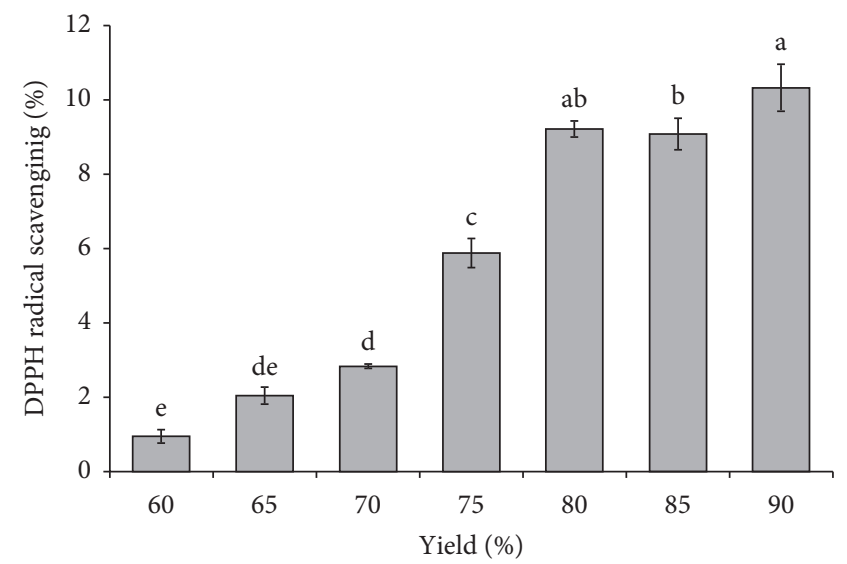

(a)

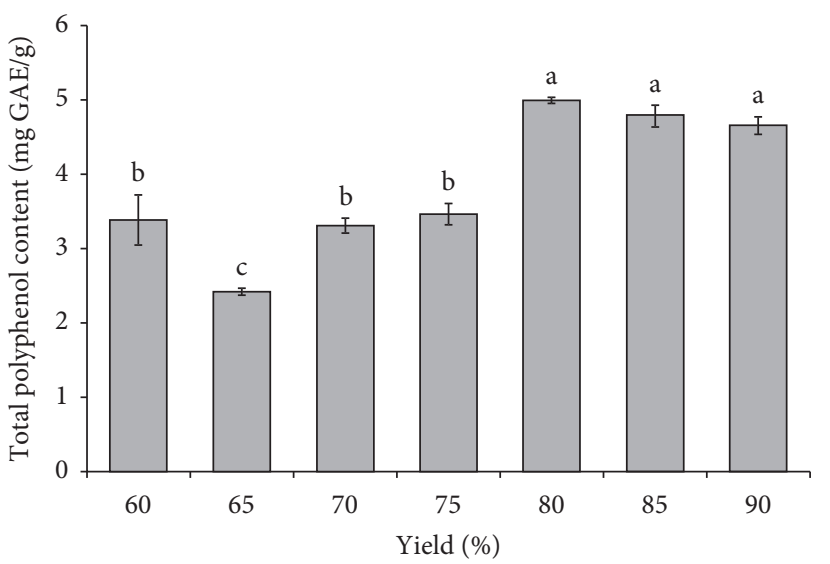

(b)

FIGURE 1: DPPH radical scavenging activity (a) and total polyphenol content (b) of wheat flour (var. Jokyoung) based on yield. Error bars represents standard deviations. Different characters within each graph are significantly different across the samples at $p<0.05$ by Fisher's least significant difference test.

[30]. Therefore, the wheat flour from Jokyoung in this study was similar to that of the samples from the major wheatgrowing countries.

3.6. DPPH Radical Scavenging Activity and Total Polyphenol Content. The DPPH RSA of the Jokyoung wheat flour according to milling yield is shown in Figure 1(a). Y60, which was a straight flour, had the lowest DPPH RSA at $0.96 \%$, but this was slightly increased in the Y75 sample, which contained clear flour. This seemed to be additional small particles from the shorts and brans in the clear flour for Y70 and Y75. As the shorts and brans were added to the flour, the DPPH RSA increased significantly from Y75, with Y90 having the highest activity at $10.36 \%(p<0.05)$. According to P. V. Hung et al. [2], the outer layer of the wheat kernel showed stronger DPPH RSA, and as the wheat kernels were polished, the DPPH RSA decreased. Stronger DPPH RSA was observed until 30\% of the wheat kernels were polished. In this manner, our study also showed stronger DPPH RSA from $80 \%$ milling yields due to the addition of shorts and brans. Kwak and Kim [49] reported a similar DPPH RSA trend for another Korean wheat variety.

The free phenolic compounds of the Jokyoung wheat flour according to milling yields is shown in Figure 1(b). The
Y60-Y75 samples showed 2.25-3.22 mg GAE/g. This result demonstrated a similar TPC range compared to that of the imported and domestic wheat kernels (2.26-3.08 mg GAE/g) and the Keumkang variety $(3.24-3.85 \mathrm{mg}$ GAE/g) $[19,50]$. There was a slight decrease in TPC from Y80 to Y90. These free TPCs are polyphenolic compounds that can be absorbed in human intestines. The grains also contain significant amounts of bound phenolic compounds in their outer layers $[2,51]$. Since only $80 \%(\mathrm{v} / \mathrm{v})$ methanol was used in the extraction process, the bound phenolic compounds in brans were hardly extracted for analysis. The first $30 \%$ of polished wheat kernels contained significantly higher bound phenolic compounds than the inner part of the kernels [2]. The reason that samples Y80-Y90 showed the same levels of free phenolic compound contents is due to the unextracted bound phenolic compounds from brans in samples Y85 and Y90. Although bound phenolic compounds are receiving interest [51], the addition of brans to wheat flour hardly influences free phenolic compounds.

\section{Conclusions}

Approximately 30,000 tons of wheat are harvested in Korea each year; therefore, the information for milling Korean wheat is rarely known within the industry. Various yields of 
wheat flour from the addition of clear flour, shorts, and brans to straight flour affected physicochemical and antioxidant properties. Throughout this study, the wheat flour quality was identified according to the yield, and the quality change according to the yield can deliver valuable information for milling one of the two major wheat varieties in Korea. Significant changes in proximate analysis, color, SRC, RVA, and antioxidant activity were observed as the yield increased to maximize the production of wheat flour from wheat kernels. Adding clear flour and shorts (Y65-Y75) did not significantly affect the wheat flour quality in general. As brans were added to the flour portion (Y80-Y90), wheat flour quality decreased significantly due to the abundant fibers in brans. Maximizing wheat flour yield after milling is a key to minimize the production cost of Korean wheat flour, considering Korean wheat is approximately three times more expensive than the imported wheat flour. Adding a certain portion of shorts seems not to significantly influence the overall quality of wheat flour and can maximize the costbenefit in milling of Korean wheat kernels. One limitation is that this milling study was conducted using a single-year crop, the same as other researchers' milling studies; therefore, this study could not generalize the wheat flour quality for the Jokyoung variety due to not considering climate and growing conditions over several years.

\section{Data Availability}

The data used to support the findings of this study are available from the corresponding author upon request.

\section{Conflicts of Interest}

The authors declare that they have no conflicts of interest.

\section{Acknowledgments}

This research was funded by the Korea Institute of Planning and Evaluation for Technology in Food, Agriculture, and Forestry (IPET) through Agri-Bio Industry Technology Development Program, funded by the Ministry of Agriculture, Food and Rural Affairs (MAFRA) (317019-4).

\section{References}

[1] FAO cereal supply and demand brief, http://www.fao.org/ worldfoodsituation/csdb/en..

[2] P. V. Hung, T. Maeda, K. Miyatake, and N. Morita, “Total phenolic compounds and antioxidant capacity of wheat graded flours by polishing method," Food Research International, vol. 42, no. 1, pp. 185-190, 2009.

[3] Ministry of Agriculture, Food and Rural Affairs (MAFRA). Agriculture, Food And Rural Affairs Statistics Yearbook, pp. 311-342, MAFRA, Sejong, Korea, 2018.

[4] Y.-S. Choi, J.-K. Lee, Y.-H. Choi, Y.-H. Kim, C.-S. Gang, and M. Shin, "Quality characteristics of wheat flours from new released Iksan370 with long spike and domestic wheat cultivars," Korean Journal of Food and Cookery Science, vol. 31, no. 5, pp. 551-556, 2015.

[5] K.-H. Kim, C.-S. Kang, Y.-W. Seo et al., "Current regional cultural situation and evaluation of grain characteristics of
Korean wheat II. grain characteristics collected in domestic wheat cultivar grown in Korea," Korean Journal of Crop Science, vol. 58, no. 3, pp. 239-252, 2013.

[6] Increasing self-sufficient ratio of wheat by consumption expansion, http://www.agrinet.co.kr/news/articleView.html? idxno $=112278$.

[7] H. S. Kwak, T. J. Kim, E. Y. Joo et al., "Quality variation of domestic wheat compared to imported wheat depending on harvest year," Journal of the Korean Society of Food Science and Nutrition, vol. 46, no. 1, pp. 146-151, 2017.

[8] H. S. Kwak, M. J. Kim, H. Kim, and S. S. Kim, "Quality characteristics of domestic and imported commercial plain wheat flour," Korean Journal of Food Science and Technology, vol. 49, no. 3, pp. 304-310, 2017.

[9] H. S. Kwak, M. J. Kim, O.-W. Kim, and S. S. Kim, "Quality characteristics of domestic strong wheat flour," Journal of the Korean Society of Food Science and Nutrition, vol. 46, no. 5, pp. 616-621, 2017.

[10] H. S. Kwak, M. J. Kim, and S. S. Kim, "Sensory profile, consumer acceptance, and physicochemical properties of pan bread made with imported or domestic commercial wheat flour," Journal of Sensory Studies, vol. 34, no. 1, Article ID e12487, 2019.

[11] C. S. Kang, Y. K. Cheong, and B. K. Kim, "Current situation and prospect of Korean wheat industry," Food Industry and Nutrition, vol. 21, no. 2, pp. 20-24, 2016.

[12] C.-S. Kang, K.-H. Kim, Y.-W. Seo et al., "Current regional cultural situation and evaluation of grain characteristics of Korean wheat. I. survey of production practices in Korean wheat cultivar growers by region," Korean Journal of Crop Science, vol. 59, no. 1, pp. 1-15, 2014.

[13] H. S. Kwak, M. J. Kim, J. Heo et al., "Comparison of physicochemical, microbial and antioxidant properties in domestic and imported wheat kernels for bread making," Korean Journal of Food and Nutrition, vol. 31, no. 1, pp. 17-23, 2018.

[14] J.-E. Kim, S.-W. Cho, H. S. Kim et al., "Utilization of mixolab for quality evaluation in Korean wheat breeding programs," Korean Journal of Breeding Science, vol. 49, no. 1, pp. 10-22, 2017.

[15] H. Ham, I. D. Choi, H. Y. Park et al., "Phenolic compounds and radical scavenging activity of the Korean wheat (Triticum aestivum L.) according to germination times," The Korean Journal of Food And Nutrition, vol. 28, no. 5, pp. 737-744, 2015.

[16] D.-S. Shin, Y.-J. Choi, S.-T. Jeong et al., "Quality characteristics of mixed makgeolli with barley and wheat," The Korean Journal of Food And Nutrition, vol. 29, no. 4, pp. 565-572, 2016.

[17] M. J. Guttieri, B. W. Seabourn, C. Liu, P. S. Baenziger, and B. M. Waters, "Distribution of cadmium, iron, and zinc in millstreams of hard winter wheat (Triticum aestivum L.)," Journal of Agricultural and Food Chemistry, vol. 63, no. 49, pp. 10681-10688, 2015.

[18] H.-J. Liao and Y.-L. Chen, "Characteristics and protein subunit composition of flour mill streams from different commercial wheat classes and their relationship to white salted noodle quality," Cereal Chemistry Journal, vol. 92, no. 3, pp. 302-311, 2015.

[19] P. Prabhasankar, M. L. Sudha, and P. Haridas Rao, "Quality characteristics of wheat flour milled streams," Food Research International, vol. 33, no. 5, pp. 381-386, 2000.

[20] P. Fustier, F. Castaigne, S. L. Turgeon, and C. G. Biliaderis, "Impact of commercial soft wheat flour streams on dough 
rheology and quality attributes of cookies," Journal of Food Engineering, vol. 90, no. 2, pp. 228-237, 2009.

[21] M. Gómez, E. Ruiz-París, and B. Oliete, "Original article: influence of flour mill streams on cake quality," International Journal of Food Science \& Technology, vol. 45, no. 9, pp. 1794-1800, 2010.

[22] American Association of Cereal Chemists (AACC), Approved Methods of American Association of Cereal Chemists, AACC, St. Paul, MN, USA, 2000.

[23] A. E. Duyvejonck, B. Lagrain, B. Pareyt, C. M. Courtin, and J. A. Delcour, "Relative contribution of wheat flour constituents to solvent retention capacity profiles of European wheats," Journal of Cereal Science, vol. 53, no. 3, pp. 312-318, 2011.

[24] D. Lund and K. J. Lorenz, "Influence of time, temperature, moisture, ingredients, and processing conditions on starch gelatinization," C R C Critical Reviews in Food Science and Nutrition, vol. 20, no. 4, pp. 249-273, 1984.

[25] Y. Zou, M. Yang, G. Zhang, H. He, and T. Yang, "Antioxidant activities and phenolic compositions of wheat germ as affected by the roasting process," Journal of the American Oil Chemists' Society, vol. 92, no. 9, pp. 1303-1312, 2015.

[26] L. Alvarez-Jubete, H. Wijngaard, E. K. Arendt, and E. Gallagher, "Polyphenol composition and in vitro antioxidant activity of amaranth, quinoa buckwheat and wheat as affected by sprouting and baking," Food Chemistry, vol. 119, no. 2, pp. $770-778,2010$.

[27] W. Brand-Williams, M. E. Cuvelier, and C. Berset, "Use of a free radical method to evaluate antioxidant activity," $L W T$ Food Science and Technology, vol. 28, no. 1, pp. 25-30, 1995.

[28] P. Jogihalli, L. Singh, K. Kumar, and V. S. Sharanagat, "Novel continuous roasting of chickpea (Cicer arietinum): study on physico-functional, antioxidant and roasting characteristics," Lwt, vol. 86, pp. 456-464, 2017.

[29] H. S. Gujral, P. Sharma, B. S. Gill, and S. Kaur, "Effect of incorporating hydrothermal, kilned and defatted oats on antioxidant and chapatti making properties of wheat flour," Food Chemistry, vol. 138, no. 2-3, pp. 1400-1406, 2013.

[30] L. K. Berghofer, A. D. Hocking, D. Miskelly, and E. Jansson, "Microbiology of wheat and flour milling in Australia," International Journal of Food Microbiology, vol. 85, no. 1-2, pp. 137-149, 2003.

[31] Y. G. Wang, K. Khan, G. Hareland, and G. Nygard, "Distribution of protein composition in bread wheat flour mill streams and relationship to breadmaking quality," Cereal Chemistry Journal, vol. 84, no. 3, pp. 271-275, 2007.

[32] MDFS Ministry of Food and Drug Safety (MFDS), "Standard and specification of foods," 2019, https://www. foodsafetykorea.go.kr/foodcode/03_02.jsp?idx=36\#.

[33] J. Yu, S. Wang, J. Wang et al., "Effect of laboratory milling on properties of starches isolated from different flour millstreams of hard and soft wheat," Food Chemistry, vol. 172, no. 1, pp. 504-514, 2015.

[34] M. Kweon, L. Slade, and H. Levine, "Solvent retention capacity (SRC) testing of wheat flour: principles and value in predicting flour functionality in different wheat-based food processes and in wheat breeding-A review," Cereal Chemistry Journal, vol. 88, no. 6, pp. 537-552, 2011.

[35] M. J. Guttieri, C. Becker, and E. J. Souza, "Application of wheat meal solvent retention capacity tests within soft wheat breeding populations," Cereal Chemistry Journal, vol. 81, no. 2, pp. 261-266, 2004.

[36] A. Lindgren and S. Simsek, "Evaluation of hard red spring wheat mill stream fractions using solvent retention capacity test," Journal of Food Processing and Preservation, vol. 40, no. 2, pp. 131-139, 2016.

[37] S. Ram and R. P. Singh, "Solvent retention capacities of Indian wheats and their relationship with cookie-making quality," Cereal Chemistry Journal, vol. 81, no. 1, pp. 128-133, 2004.

[38] M. Schmiele, L. Z. Jaekel, S. M. C. Patricio, C. J. Steel, and Y. K. Chang, "Rheological properties of wheat flour and quality characteristics of pan bread as modified by partial additions of wheat bran or whole grain wheat flour," International Journal of Food Science \& Technology, vol. 47, no. 10, pp. 2141-2150, 2012.

[39] S. Ragaee and E.-S. M. Abdel-Aal, "Pasting properties of starch and protein in selected cereals and quality of their food products," Food Chemistry, vol. 95, no. 1, pp. 9-18, 2006.

[40] J. Blazek and L. Copeland, "Pasting and swelling properties of wheat flour and starch in relation to amylose content," Carbohydrate Polymers, vol. 71, no. 3, pp. 380-387, 2008.

[41] I. S. M. Zaidul, H. Yamauchi, S.-J. Kim, N. Hashimoto, and T. Noda, "RVA study of mixtures of wheat flour and potato starches with different phosphorus contents," Food Chemistry, vol. 102, no. 4, pp. 1105-1111, 2007.

[42] S. Hug-Iten, F. Escher, and B. Conde-Petit, "Staling of bread: role of amylose and amylopectin and influence of starchdegrading enzymes," Cereal Chemistry Journal, vol. 80, no. 6, pp. 654-661, 2003.

[43] J. H. Kim, E. J. Tanhehco, and P. K. W. Ng, "Effect of extrusion conditions on resistant starch formation from pastry wheat flour," Food Chemistry, vol. 99, no. 4, pp. 718-723, 2006.

[44] C. G. Biliaderis, C. M. Page, T. J. Maurice, and B. O. Juliano, "Thermal characterization of rice starches: a polymeric approach to phase transitions of granular starch," Journal of Agricultural and Food Chemistry, vol. 34, no. 1, pp. 6-14, 1986.

[45] D. Cooke and M. J. Gidley, "Loss of crystalline and molecular order during starch gelatinisation: origin of the enthalpic transition," Carbohydrate Research, vol. 227, pp. 103-112, 1992.

[46] A.-C. Eliasson, J. Silverio, and E. Tjerneld, "Surface properties of wheat flour-milling streams and rheological and thermal properties after hydration," Journal of Cereal Science, vol. 13, no. 1, pp. 27-39, 1991.

[47] L. Wannerberger and A. C. Eliasson, "Differential scanning calorimetry studies on rye flour-milling streams," Cereal Chemistry, vol. 70, p. 196, 1993.

[48] D. Mares and K. Mrva, "Late-maturity $\alpha$-amylase: low falling number in wheat in the absence of preharvest sprouting," Journal of Cereal Science, vol. 47, no. 1, pp. 6-17, 2008.

[49] M. Vaher, K. Matso, T. Levandi, K. Helmja, and M. Kaljurand, "Phenolic compounds and the antioxidant activity of the bran, flour and whole grain of different wheat varieties," Procedia Chemistry, vol. 2, no. 1, pp. 76-82, 2010.

[50] N. Victor, M. S. Bekele, M. Ntseliseng, M. Makotoko, C. Peter, and A. O. Asita, "Microbial and physicochemical characterization of maize and wheat flour from a milling company, lesotho," Internet Journal of Food Safety, vol. 15, pp. 11-19, 2013.

[51] S. S. Kim and H. S. Kwak, "Quality characteristics of domestic wheat flour (var. Keumkang) based on the milling yield," Journal of the Korean Society of Food Science and Nutrition, vol. 48, no. 8, pp. 879-886, 2019. 